\title{
DESENVOLVIMENTO DE UM MODELO CHUVA-VAZÃO VIA TANK MODEL E CALIBRAÇÃO AUTOMÁTICA
}

\section{Development of a Rainfall-runoff model by means of Tank Model and Automatic Calibration}

\author{
Tatiane Souza Rodrigues Pereira ${ }^{1}$, Kamila Almeida dos Santos ${ }^{2}$, Bruna Ferreira da Silva ${ }^{3}$, \\ Klebber Teodomiro Martins Formiga ${ }^{4}$ e Alexandre Kepler Soares ${ }^{5}$
}

Recebido em 03 de julho de 2015; recebido para revisão em 28 de janeiro de 2016; aceito em 18 de março de 2016; disponivel on-line em 11 de maio de 2016.

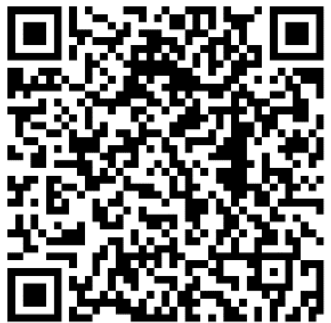

PALAVRAS CHAVE:

Modelagem hidrológica; Programação não-linear; Algoritmo evolucionário; Bacia hidrográfica; Vazão.

\section{KEYWORDS:}

Hydrologic modeling; Nonlinear programming; Evolutionary algorithm; Catchment; Streamflow.

* Contato com os autores:

${ }^{1}$ e-mail : tatiane.srp@hotmail.com ( T. S. R. Pereira )

Engenheira Ambiental, Doutoranda em Ciências Ambientais pela Universidade Federal de Goiás.

2e-mail : kamilas.geo@gmail.com (K. A. dos Santos )

Tecnóloga em Geoprocessamento e Mestre em Engenharia do Meio Ambiente pela Universidade Federal de Goiás.

${ }^{3}$ e-mail : brunaferreiraciamb@hotmail.com (B. F. da Silva )

Bacharel em Ciências Ambientais e Mestre em Engenharia do Meio Ambiente, Universidade Federal de Goiás.

${ }^{4}$ e-mail : klebber.formiga@gmail.com (K. T. M. Formiga )

Engenheiro Civil, Doutor, Professor da Escola de Engenharia Civil e Ambiental da Universidade Federal do Goiás - EECA/UFG. ${ }^{5}$ e-mail : aksoares@gmail.com (A. K. Soares )

Engenheiro Civil, Doutor, Professor da Escola de Engenharia Civil e Ambiental da Universidade Federal do Goiás - EECA/UFG. 


\section{INTRODUÇÃO}

As séries hidrológicas são de fundamental importância para a gestão e planejamento dos usos múltiplos dos recursos hídricos. Assim, a existência de uma série consistente é imprescindível. No entanto, em diversas regiões do Brasil, é notável a carência de registros históricos de séries hidrológicas, principalmente de vazões. A fim de evitar que certos estudos ligados a Hidrologia sejam inviabilizados devido a este fato, nas últimas décadas, tem-se desenvolvido e aperfeiçoado diversos modelos hidrológicos para a reprodução do processo de transformação de chuva em vazão. No entanto, esses modelos ainda necessitam ser mais estudados, para que estes não induzam a um nível considerável de inconsistência e heterogeneidade nos dados sintéticos, que podem estar ligados a diversos fatores. Um deles é a escala temporal, que tem demonstrado influência direta nas simulações dos modelos.

Dentre os diversos modelos hidrológicos, - Tank Model é um modelo de chuva-vazão recomendado para simulação de balanço hídrico por gerar bons resultados quanto ao cálculo das vazões de pico e do volume escoado superficialmente (Lara e Kobiyama, 2012), além de apresentar configuração simples e $\mathrm{o}$ seu desempenho já ter sido reportado em estudos prévios, como os realizados por WMO (1975) e FRANCHINI e PACCIANI (1991). O Tank Model tratase de um modelo que tem sido amplamente empregado no estudo de cheias, preenchimento de falhas de séries hidrológicas e na avaliação das disponibilidades hídricas de bacias hidrográficas, principalmente em países da Ásia, com ênfase no Japão. No Brasil, o Tank Model também tem sido utilizado, porém de maneira localizada, como no caso do Estado da Paraíba, que possui diversos estudos na área devido a parcerias Brasil-Japão realizadas pela Universidade Federal da Paraíba (JÚNIOR et al., 2009; SANTOS et al., 2011).

Embora os modelos em geral apresentem ter muitas vantagens, estes possuem como caraterística a dificuldade de calibração. No caso do Tank Model, a dificuldade na calibração é devido à arbitrariedade na obtenção das variáveis de ajuste.

Assim, o sucesso no alcance de bons resultados irá depender da habilidade do modelador, bem como das técnicas de calibração a serem empregadas.

Atualmente, problemas de calibração têm sido tratados como problemas de otimização, nos quais as variáveis de decisão do modelo são determinadas. Como procedimento típico para estimativa dos valores das variáveis de decisão, considera-se a função objetivo, o algoritmo de otimização e o critério de parada (BRAVO et al., 2007). Tradicionalmente, o que se procura é ter uma discrepância mínima entre as previsões do modelo e as observações, ou seja, um erro mínimo cometido na estimativa do modelo, que também pode ser convertido em termos de eficiência deste.

Tradicionalmente, os problemas de calibração podem ser resolvidos por técnicas de programação linear (PL) ou programação não-linear (PNL). No entanto, tais técnicas apresentam limitações quando utilizadas na resolução de problemas muito complexos, multiobjetivos, não convexos não-lineares, além da dificuldade em se encontrar ótimos globais, gerando assim a procura por outros algoritmos (Singh, 2014). Dessa forma, os Algoritmos Genéticos (AG) (Rechenberg, 1973; Holland, 1975; Goldberg, 1989) foram instituídos como uma valiosa ferramenta na resolução desses problemas (Nicklow et al., 2010), pois têm a capacidade de realizar uma busca por aquela solução que seja muito boa ou que melhor se ajusta ao problema, levando assim a otimização da função objetivo.

\section{OBJETIVOS}

Este estudo visa comparar os resultados da calibração e validação do modelo Tank Model empregando dois algoritmos (Gradiente Reduzido Generalizado não-linear e Algoritmo Genético), bem como, avaliar os resultados da aplicação do modelo para escalas temporais distintas (mensal e diária) para a Bacia Hidrográfica do Rio Manoel Alves da Natividade. 


\section{MATERIAL E MÉTODOS}

\subsection{DESCRIÇÃO DA ÁREA DE ESTUDO}

A Bacia Hidrográfica do Rio Manoel Alves da Natividade está localizada no estado do Tocantins, faz divisa com a Bahia ao leste do Estado, e possui área de drenagem de $14.894,7 \mathrm{~km}^{2}$, conforme Figura 1. Afluente do rio Tocantins pela margem direita, a bacia pertence ao Aquífero Urucuia e possui alto potencial hidrogeológico, com grande capacidade de armazenamento e vazão, sendo responsável pela perenização e recarga dos rios nos períodos de estiagem (Mamede et al., 2002). Ela ocupa aproximadamente $5,4 \%$ da área total do Estado do Tocantins e abrange 12 municípios: Almas, Chapada de Natividade, Conceição do Tocantins, Dianópolis, Natividade, Paraná, Pindorama, Porto Alegre do Tocantins, Rio da Conceição, Santa Rosa do Tocantins, São Valério da Natividade e Taipas do Tocantins. Segundo a SEPLAN-TO (2011), o clima da região é tropical semi-úmido, com temperatura média anual variando entre $25^{\circ} \mathrm{C}$ e $29^{\circ} \mathrm{C}$; possui vegetação do tipo Cerrado, cobrindo cerca de $87 \%$ do território com $12 \%$ por florestas de transição. Os tipos de solo encontrados na região de estudo são: cambissolo, plintossolo, gleissolo, latossolo, nitossolo, argissolo, neossolo e planossolos.

Atualmente, a bacia do Rio Manoel Alves da Natividade está inserida em programas específicos do governo voltados à água, que preveem a construção de 15 pequenas centrais hidrelétricas e 16 usinas hidrelétricas no estado. Assim, esta vem sendo considerada como potencial área de produção energética, com previsão de potência de aproximadamente $72 \mathrm{MW}$ (Governo Tocantins, 2013).

Os dados utilizados nas análises deste estudo foram disponibilizados pela Agência Nacional de Águas - ANA. O banco de dados é composto por informações de precipitação, temperatura e vazão. As séries de cada variável possuem 33 anos, com início no ano de 1973 e fim em 2006. De acordo com Farmer et al. (2003), uma extensão de 15 anos das séries temporais dos dados é considerada representativa para análises hidrológicas. Os primeiros 13 anos da série de vazões foram aplicados para a calibração do modelo, e os anos seguintes para validação.

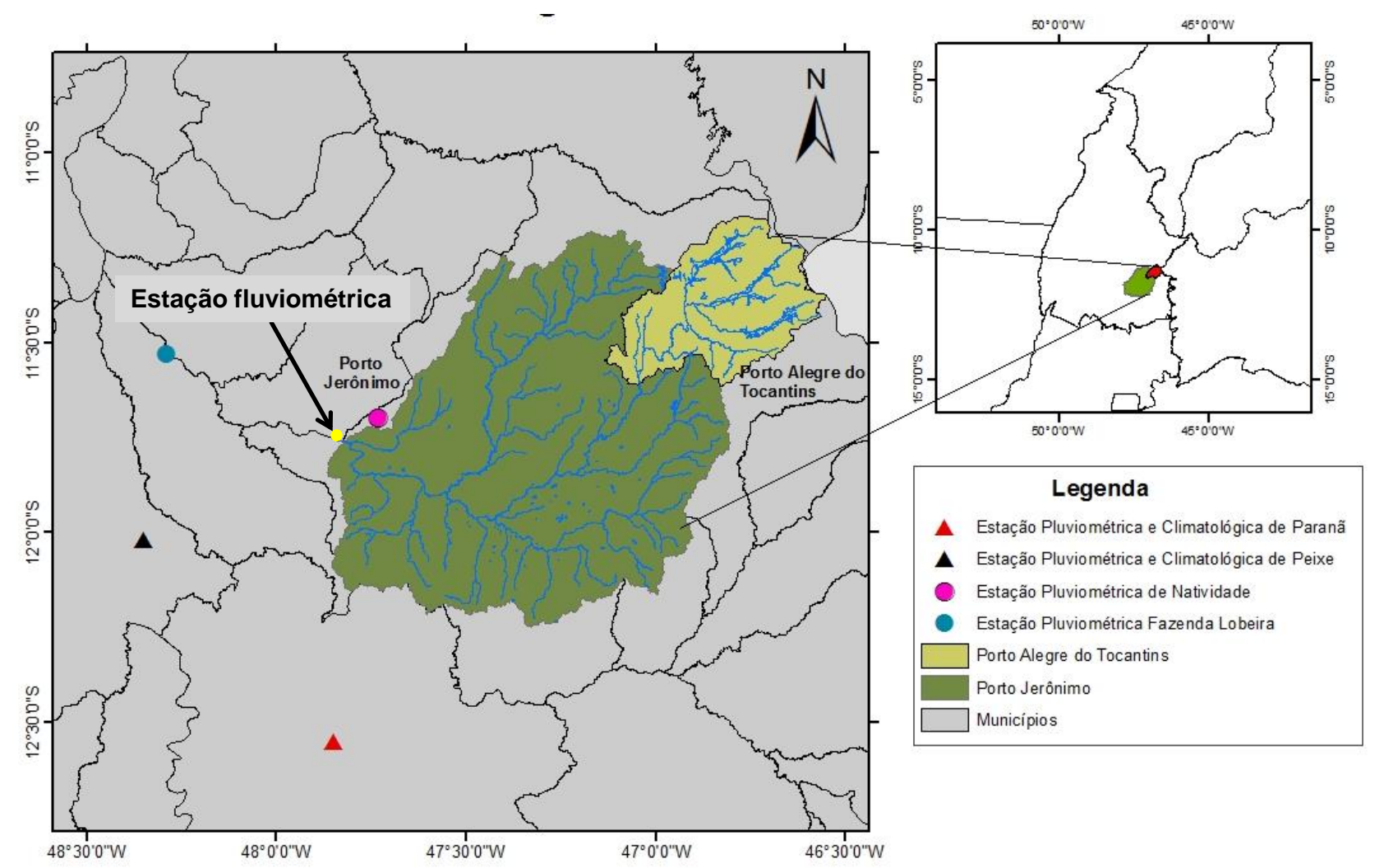

FIGURA 1: Localização da Bacia Hidrográfica do Rio Manoel Alves da Natividade e das estações fluviométrica e pluviométricas.

FONTE: os autores. 
Foram utilizados dados da estação fluviométrica de Porto Jerônimo e de quatro estações pluviométricas mais próximas da bacia hidrográfica, conforme apresentadas na Figura 1. As séries de temperatura utilizadas foram as pertencentes aos municípios de Fátima e Filadélfia, escolhidas para representar a temperatura de toda a região da bacia, uma vez que o clima destas possuem características semelhantes ao clima regional, mas principalmente devido à ausência de dados climatológicos na bacia.

Os valores de evapotranspiração foram calculados pelo método de Thornthwaite e Mather (1957), no qual por meio da latitude e de temperaturas médias mensais do ar, consegue-se estimar a evapotranspiração potencial mensal e diária da região. Para sua aplicação, são necessários dados de no mínimo 30 anos. Numa escala intermediária, como no caso do estudo de pequenas e médias bacias, o método é indicado, pois consegue representar o balanço hídrico de forma aceitável. Esse método foi escolhido devido à ausência de dados climatológicos na bacia, que por outros métodos como o de Penman-Monteith (Monteith, 1973), um dos mais indicados para cálculo do balanço hídrico, tornaria o desenvolvimento do estudo inviável, uma vez que com os dados disponíveis não se conseguiria estimar valores confiáveis para as precipitações de referência, bem como para os coeficientes de evapotranspiração.

\subsection{TANK MODEL}

O Tank Model permite simular o balanço hídrico de uma bacia hidrográfica utilizando um conjunto de tanques em série, em que o armazenamento do primeiro tanque é determinado pela chuva e o armazenamento dos demais tanques é determinado pela infiltração do tanque superior (Lara e Kobiyama, 2012).

A Figura 2 demonstra o esquema dos transientes utilizados neste estudo. O sistema é constituído por dois tanques, devido às características climáticas da região, predominantemente seca, e é responsável pela simulação do balanço de massa e da propagação do hidrograma. Assim, segundo Galvão e Valença (1999), a descarga de água no primeiro tanque, através das duas saídas laterais, corresponde, conceitualmente, aos escoamentos de superfície e hipodérmico. A água no segundo tanque que eflui por meio da saída lateral é equivalente ao escoamento intermediário. O fluxo através da saída lateral do último tanque corresponde ao fluxo de base ou subterrâneo. Dessa forma, a soma total de todas essas saídas laterais, corresponde à vazão do rio na seção considerada.
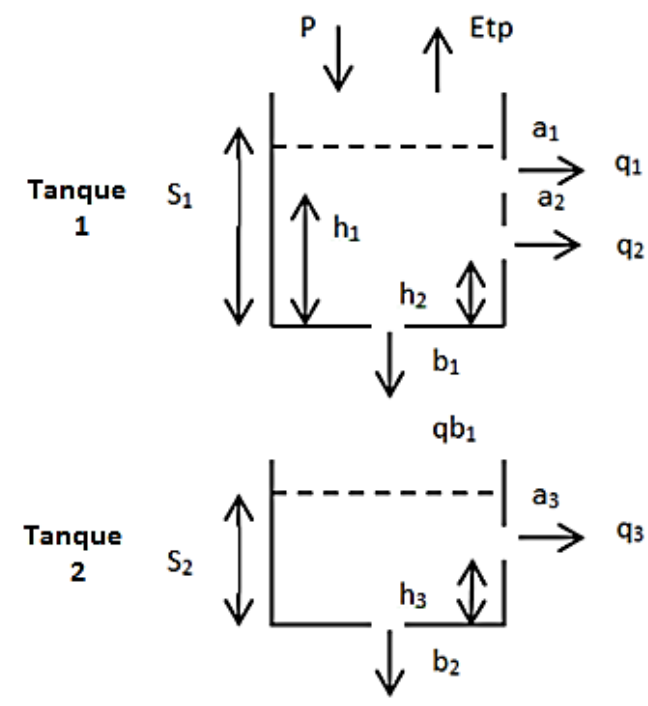

$\mathrm{qb}_{2}$

FIGURA 2: Esquema do Tank Model utilizado.

FONTE: os autores.

Na qual:

$\mathbf{P}=$ lâminas de precipitação;

$\mathbf{S}_{1}$ e $\mathbf{S}_{2}=$ alturas das lâminas d'água armazenadas nos tanques;

Etp = evapotranspiração potencial;

$\mathbf{a}_{1}, \mathbf{a}_{2}$ e $\mathbf{a}_{3}=$ coeficientes de vazão lateral;

$\mathbf{b}_{1}$ e $\boldsymbol{b}_{\mathbf{2}}=$ coeficientes de vazão de fundo;

$h_{1}, h_{2}$ e $h_{3}=$ alturas dos orifícios das saídas laterais;

$\mathbf{q}_{1}, \mathbf{q}_{2}$ e $\mathbf{q}_{\mathbf{3}}=$ escoamento superficial; $\mathrm{e}$ $\mathbf{q} \mathbf{b}_{1}$ e $\mathbf{q} \mathbf{b}_{\mathbf{2}}=$ descargas de fundo

Para determinação da vazão lateral $\mathrm{q}_{1}$ (Equação 2), para cada tempo t (mês ou dia) de cada ano no primeiro orifício lateral $\mathrm{a}_{1}$, é realizado o balanço hídrico para altura de água armazenada $\mathrm{S}_{1(\mathrm{a} 1, \mathrm{t})}$, conforme Equação 1:

$$
S_{1(a 1, t)}=S_{1(t 1)}+P_{(t)}-E_{t p}(t) \cdot K
$$

Sendo: $K=$ coeficiente de evapotranspiração. Se $S_{1(a 1, t)}>0$, indica que haverá escoamento $q_{1(t)}$ no 
orifício, mostrando a altura d'água armazenada. Caso contrário, $\mathrm{q}_{1(\mathrm{t})}$ será nulo.

$\mathrm{Na}$ Equação 2, se $S_{1(\mathrm{a} 1, \mathrm{t})}>h_{1}$, então $\mathrm{q}_{1(\mathrm{t})}>0$, ou seja, se a altura da lâmina d'água for maior que a altura do orifício, haverá escoamento. Senão, $\mathrm{q}_{1(\mathrm{t})}=0$, indicando que não haverá escoamento no orifício, ou seja, se a altura da lâmina d'água no tanque for menor que a do orifício, não haverá escoamento.

$$
\mathrm{q}_{1(\mathrm{t})}=\mathrm{a}_{1} \cdot\left(\mathrm{S}_{1(\mathrm{a} 1, \mathrm{t})}-\mathrm{h}_{1}\right)
$$

Para a determinação da vazão lateral $q_{2}$ (Equação 3), para cada tempo $t$ de cada ano (mês ou dia) no segundo orifício lateral $a_{2}$, é realizada a diferença entre $o$ balanço hídrico de armazenamento $S_{1(a 1, t)}$ e a vazão $q_{1(t)}$, que mostrará como resultado a altura de lâmina d'água armazenada $\mathrm{S}_{1(\mathrm{a} 2, \mathrm{t})}$ após a saída dessa vazão.

$$
q_{2(t)}=a_{2} \cdot\left(S_{1(a 2, t)}-h_{2}\right) \quad \text { Eq. [3] }
$$

$\mathrm{Na}$ Equação 3, se $S_{1(\mathrm{a} 2, \mathrm{t})}>h_{2}$, então $\mathrm{q}_{2(\mathrm{t})}>0$, ou seja, se a altura da lâmina d'água for maior que a altura do orifício, haverá escoamento. Senão, $q_{2(t)}=0$, indicando que não haverá escoamento no orifício, ou seja, se a altura da lâmina d'água for menor que a do orifício, não haverá escoamento.

Para determinação da vazão ou descarga de fundo $q b_{1(t)}$ (Equação 4), para um tempo $t$ de cada ano (mês ou dia) no primeiro orifício de fundo $b_{1}$, é necessário, primeiramente, conhecer o valor da altura de lâmina d'água armazenada $S_{1(b 1, t)}$ após as saídas laterais. Para isso, é realizado o cálculo da diferença entre a altura de lâmina d'água armazenada $\mathrm{S}_{1(\mathrm{a}, \mathrm{t})}$ e a vazão de saída lateral $\mathrm{q}_{2(\mathrm{t})}$.

$O$ resultado encontrado para $S_{1(b 1, t)}$, ou seja, o que se tem de água reservada após todas as saídas laterais, é utilizado para o cálculo da vazão de saída de fundo. Assim, a vazão de fundo $q b_{1(t)}$ é obtida pela Equação 4:

$$
q b_{1(t)}=b_{1} \cdot S_{1(b 1, t)}
$$

Uma vez conhecida a vazão de fundo $\mathrm{qb}_{1(\mathrm{t})}$, é possível encontrar qual a altura final de lâmina d'água armazenada $S_{1(t \text { final) }}$ no tanque 1 após todas as saídas de vazões laterais e de fundo, pela diferença entre a altura armazenada $S_{1(b 1, t)}$ e a vazão de saída de fundo $q b_{1(t)}$.
Dessa forma, $\mathrm{S}_{1(\text { t final) }}$ (Equação 5) passará a ser a altura inicial de lâmina d'água armazenada no tempo $t+1$, ou seja, cada nova altura de lâmina encontrada para cada mês ou dia passará a ser o armazenamento inicial para o tempo seguinte, e assim sucessivamente.

$$
\mathrm{S}_{1(\mathrm{t} \text { final })}=\mathrm{S}_{1(\mathrm{t}+1 \text { inicial })}
$$

Como o armazenamento no próximo tanque é determinado pela infiltração do tanque superior, a altura de lâmina d'água armazenada $S_{2(a 3, t)}$ será o somatório entre a altura de água reservada inicialmente nesse tanque, $S_{2(\text { inicial), e a }}$ vazão de descarga de fundo $q b_{1(t)}$ do tanque 1 . Uma vez conhecida a altura da lâmina, é possível calcular a vazão lateral $\mathrm{q}_{3(\mathrm{t})}$ pela Equação 6 :

$$
q_{3(t)}=a_{3} .\left(S_{2(a 3, t)}-h_{3}\right)
$$

$\mathrm{Na}$ Equação 6, se $S_{2(a 3, t)}>h_{3}$, então $\mathrm{q}_{3(\mathrm{t})}>0$, ou seja, se a altura da lâmina d'água for maior que a do orifício, haverá escoamento. Senão, $\mathrm{q}_{3(\mathrm{t})}=0$, indicando que não haverá escoamento no orifício, ou seja, se a altura da lâmina d'água for menor que a do orifício, não haverá escoamento.

Após conhecida a vazão de saída, pode-se obter a altura de lâmina d'água $S_{2(b 2, t)}$ do reservatório pela diferença entre a altura $S_{2(a 3, t)}$ e a vazão lateral $\mathrm{q}_{3(\mathrm{t})}$. A altura $\mathrm{S}_{2(\mathrm{~b} 2, \mathrm{t})}$ é utilizada para calcular a vazão de descarga de fundo $q b_{2(t)}$, segundo a Equação 7:

$$
q b_{2(t)}=b_{2} \cdot S_{2(b 2, t) \quad \text { Eq. [7] }}
$$

Após determinada a vazão $q b_{2(t)}$, considerada como "perda" para o lençol subterrâneo, obtém-se a altura de lâmina d'água final $S_{2(t \text { final) }}$ no tanque 2 pela diferença entre altura de lâmina d'água $S_{2(b 2, t)}$ e a vazão de saída de fundo $q b_{2(t)}$.

Assim, da mesma forma que para o tanque 1, $\mathrm{S}_{2(t \text { tinal) }}$ (Equação 8) passará a ser a altura inicial de lâmina d'água armazenada no tempo $t+1$, ou seja, cada nova altura de lâmina encontrada para cada mês ou dia passará a ser o armazenamento inicial para o tempo seguinte e, assim, sucessivamente.

$$
S_{2(t \text { final })}=S_{2(t+1 \text { inicial })}
$$

Por fim, a vazão de saída mensal ou diária

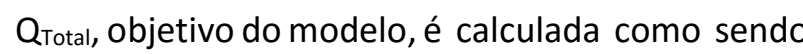


a soma das descargas laterais $\mathrm{q}_{1}, \mathrm{q}_{2}$ e $\mathrm{q}_{3}$. Essa vazão calculada é o dado de saída do modelo, ou seja, é o volume de água escoado pelo rio na seção considerada por unidade de tempo para o período estudado.

\subsection{MODELO INVERSO}

Os dados observados de precipitação e evapotranspiração referem-se a dados mensais e diários, e os de vazões observadas, referem-se a dados mensais. Neste estudo, são realizadas duas abordagens, sendo uma da modelagem hidrológica aplicada para dados mensais e outra para dados diários. Assim, visa-se obter séries de vazões "sintéticas" mensais para os dois modelos a fim de verificar qual série sintética possui melhor representatividade da realidade na modelagem pelo Tank Model, ou seja, qual série se ajusta aos dados observados de vazões. Para isso, após implementação do Tank Model, segue-se a calibração do modelo. Neste estudo, foram utilizados dois métodos automáticos de calibração do módulo Solver para fins de comparação das soluções: o Método de Programação não-linear do Gradiente Reduzido Generalizado (GRG) e o método do Algoritmo Genético (AG).

A calibração automática passou a ser bastante utilizada pelo fato de proporcionar maior rapidez e menor subjetividade ao processo. Nesse método, a busca por um vetor adequado de parâmetros ocorre por meio de métodos matemáticos de otimização, podendo ser obtida pela minimização ou maximização de uma função objetivo que mede o desvio entre as séries de vazão observada e simulada. A função objetivo é a representação matemática desta diferença, e a calibração busca um vetor de parâmetros representativo, capaz de encontrar o ponto ótimo dessa função. A cada passo, o algoritmo calcula novo valor da função objetivo, compara com o último valor calculado e segue na direção do valor ou ponto ótimo para a função objetivo, quando então se verifica a convergência, encerra-se o processo iterativo (TUCCl et al., 1981; GERMANO et al., 1998).

Dessa forma, modelo inverso aplicado visa tornar os valores simulados de vazões tão próximos quanto possível aos valores observados, ou seja, visa a otimização por meio da maximização da função objetivo não-linear definida pelo coeficiente de eficiência de Nash-Sutcliffe (1970) (eNS), conforme Equação 9.

$$
\max e N S=1-\frac{\sum\left(Q_{\text {obs }}-Q_{\text {calc }}\right)^{2}}{\sum\left(Q_{\text {obs }}-Q_{\text {méd }}\right)^{2}}
$$

Na qual:

eNS = coeficiente de Nash-Sutcliffe;

$\mathbf{Q}_{\text {obs }}=$ vazão observada;

$\mathbf{Q}_{\text {calc }}=$ vazão calculada pelo modelo chuva-vazão;

$\mathbf{Q}_{\text {méd }}=$ vazão média observada.

O coeficiente de eNS é utilizado para avaliar o poder preditivo de modelos hidrológicos em termos de eficiência, podendo variar entre $-\infty$ e 1. Dessa forma, se o valor da eficiência for igual a 1 , os valores modelados correspondem a uma combinação perfeita aos dados observados. Se a eficiência for igual a zero, as previsões do modelo são tão exatas quanto a média dos dados observados, e se a eficiência for menor do que zero indica que a média dos dados observados é melhor do que o modelo, ou seja, quando a variância residual descrita pelo numerador da equação, é menor do que a variância dos dados descritos pelo denominador (NASH e SUTCLIFFE, 1970).

Os parâmetros a serem calibrados (variáveis de decisão) são: os coeficientes de vazão lateral, os coeficientes de vazão de fundo, as alturas dos orifícios e o coeficiente de evaporação. As variáveis de estado do modelo são as vazões observadas e vazão média observada.

\section{RESULTADOS E DISCUSSÕES}

Os parâmetros para os modelos mensal e diário foram calibrados para o período 1973 a 1986 e realizada a validação para o período de 1987 a 2006.

Os resultados obtidos para os parâmetros (Tabela 1), foram os mesmos utilizando os dois métodos de otimização, com alteração de alguns dos valores apenas a partir da sexta casa decimal. $O$ método GRG apresentou processo de otimização mais rápido, com tempo de processamento de 
cerca de 100 s para um computador com processador Intel(R) Core(TM) i3 CPU 2,53GHz e memoria RAM 2GB. Em relação ao método do Algoritmo Genético, o tempo de processamento foi 24 vezes maior do que o do GRG, ou seja, cerca de 41 min para atingir convergência. Esse fato pode ser entendido devido ao Algoritmo Genético ter sido desenvolvido para solução de problemas complexos, utilizando técnicas matemáticas no processamento mais intricados do que as empregadas no algoritmo GRG, necessitando assim de mais tempo para processar os dados.

Os resultados da calibração, representados pelos coeficientes de eNS obtidos, podem ser considerados satisfatórios em termos de simulação hidrológica, uma vez que o modelo foi capaz de obter precisão da ordem de $89 \%$ e 95\% da variância nas séries de vazões mensais e diárias observadas, respectivamente. Isso demonstrou uma boa qualidade dos resultados de simulação do conjunto de parâmetros.

Os fluviogramas dos processos de calibração e validação mensais e diários são apresentados nas Figuras 3 a 10. As hidrógrafas das vazões diárias calculadas apresentaram baixa sincronia em relação às vazões observadas, além de a configuração geral não representar satisfatoriamente os picos de cheias e nem os períodos de recessão (Figuras 5, 6, 9 e 10). O mesmo não ocorreu para as hidrógrafas da calibração mensal calculada com relação às vazões mensais observadas, em que o modelo conseguiu apresentar sincronia entre as séries (Figuras 3, 4, 7 e 8).

Assim, a configuração mensal apresentou ter boa representatividade quando empregada na modelagem pelo Tank Model, pois existe superestimação dos picos de cheia pela configuração diária, bem como subestimação dos períodos de recessão ou seca. Sendo assim, e considerando os resultados deste estudo, recomenda-se o emprego de vazões mensais na modelagem chuva-vazão empregando o Tank Model.

TABELA 1: Parâmetros calibrados pelos métodos GRG e AG para o Tank Model a partir de vazões mensais e diárias.

\begin{tabular}{ccc} 
Parâmetro & Vazão mensal & Vazão diária \\
\hline $\mathrm{a}_{\mathbf{1}}$ & 0,276 & 0,049 \\
\hline $\mathrm{a}_{\mathbf{2}}$ & 0,090 & 0,006 \\
\hline $\mathrm{a}_{\mathbf{3}}$ & 1,000 & 0,678 \\
\hline $\mathrm{b}_{\mathbf{1}}$ & 0,331 & 0,022 \\
\hline $\mathrm{b}_{\mathbf{2}}$ & 0,724 & 1,000 \\
\hline $\mathrm{h}_{\mathbf{1}}$ & $400,0 \mathrm{~mm}$ & $256,9 \mathrm{~mm}$ \\
\hline $\mathrm{h}_{\mathbf{2}}$ & $55,0 \mathrm{~mm}$ & $0,0 \mathrm{~mm}$ \\
\hline $\mathbf{h}_{\mathbf{3}}$ & $250,0 \mathrm{~mm}$ & $250,0 \mathrm{~mm}$ \\
\hline eNS (calibração) & 0,894 & 0,952 \\
\hline eNS (validação) & 0,675 & 0,795 \\
\hline
\end{tabular}

FONTE: os autores. 


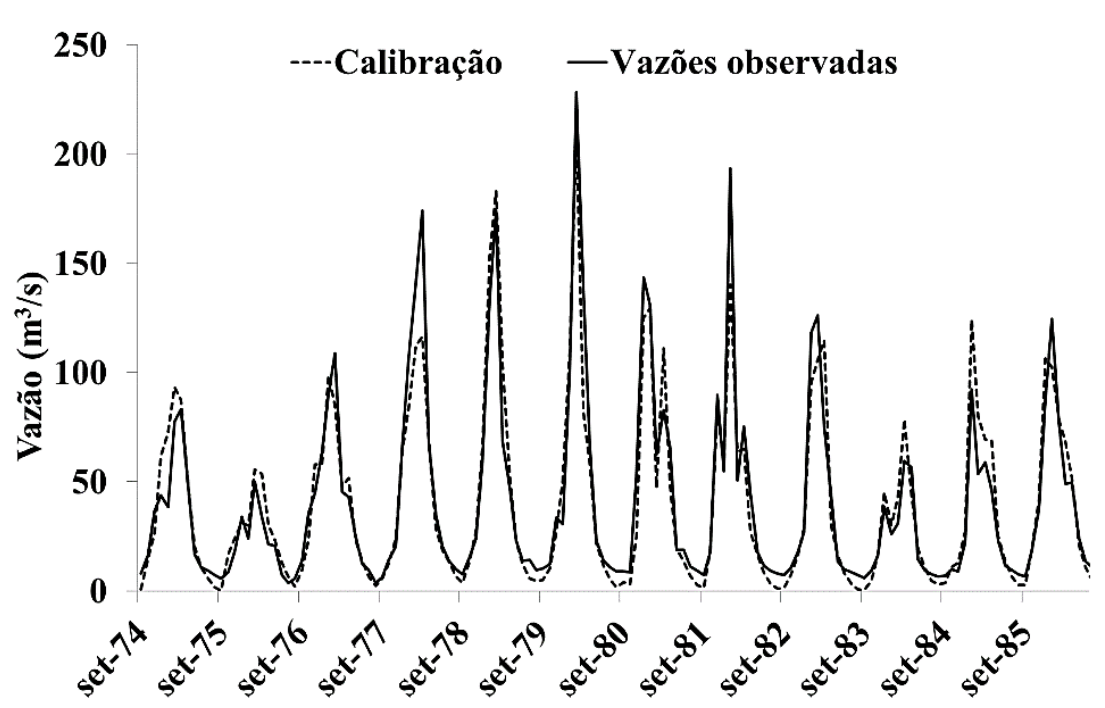

FIGURA 3: Calibração em termos das vazões mensais observadas: método GRG não linear. FONTE: os autores.

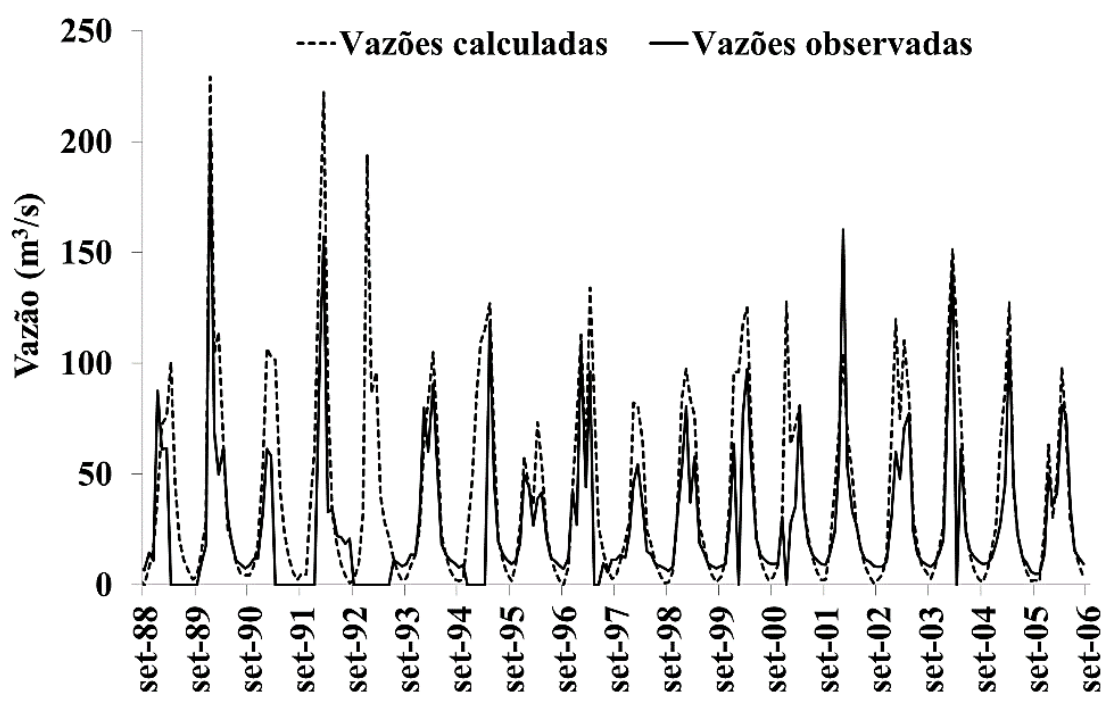

FIGURA 4: Validação em termos das vazões mensais observadas: método GRG não linear. FONTE: os autores.

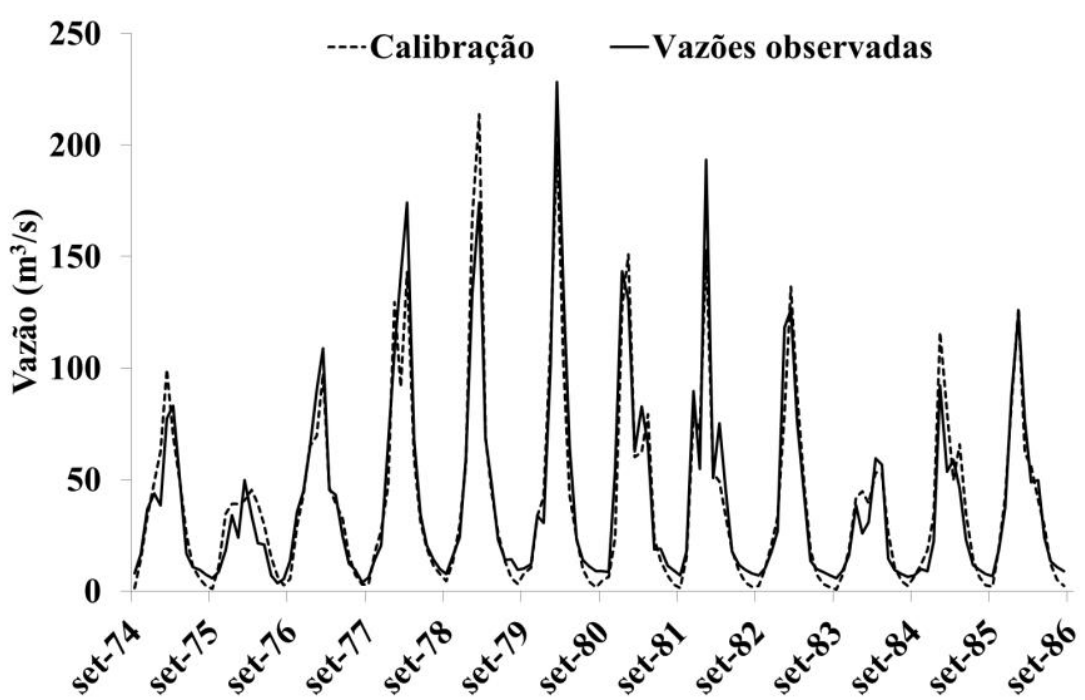

FIGURA 5: Calibração em termos das vazões diárias observadas: método GRG não linear. FONTE: os autores. 


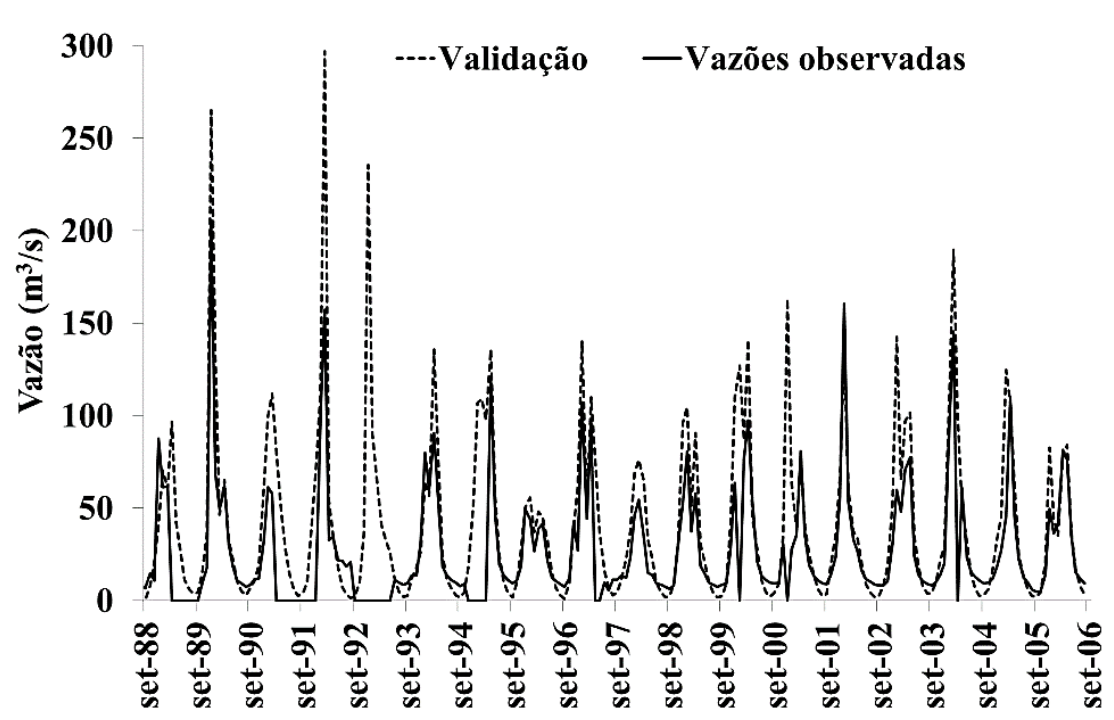

FIGURA 6: Validação em termos das vazões diárias observadas: método GRG não linear. FONTE: os autores.

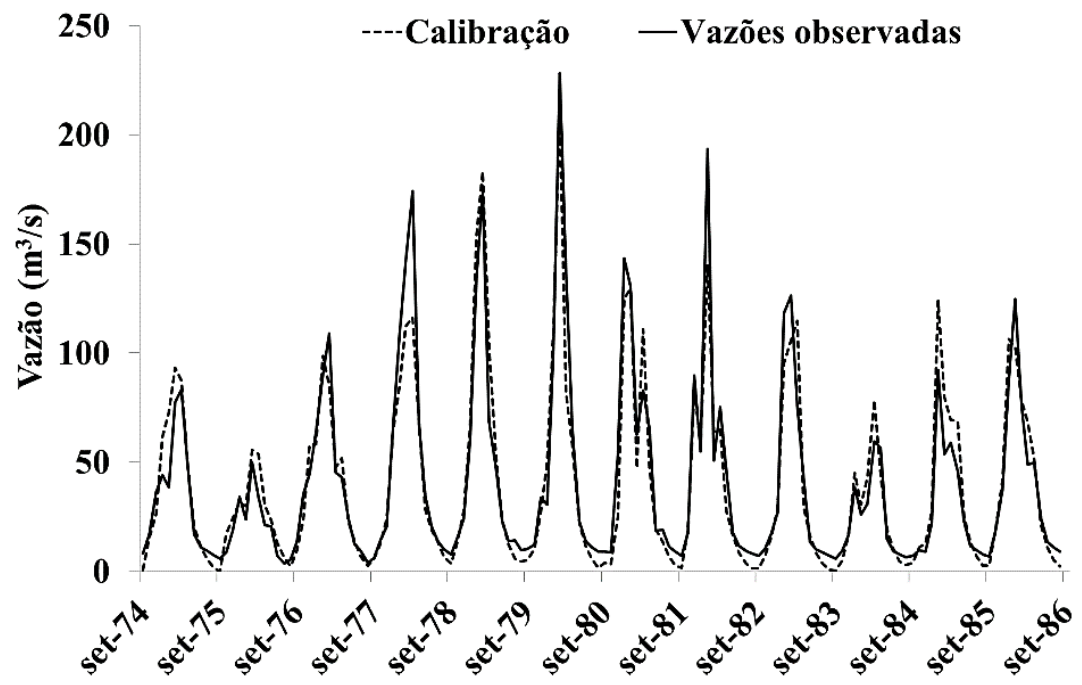

FIGURA 7: Calibração em termos das vazões mensais observadas: método AG. FONTE: os autores.

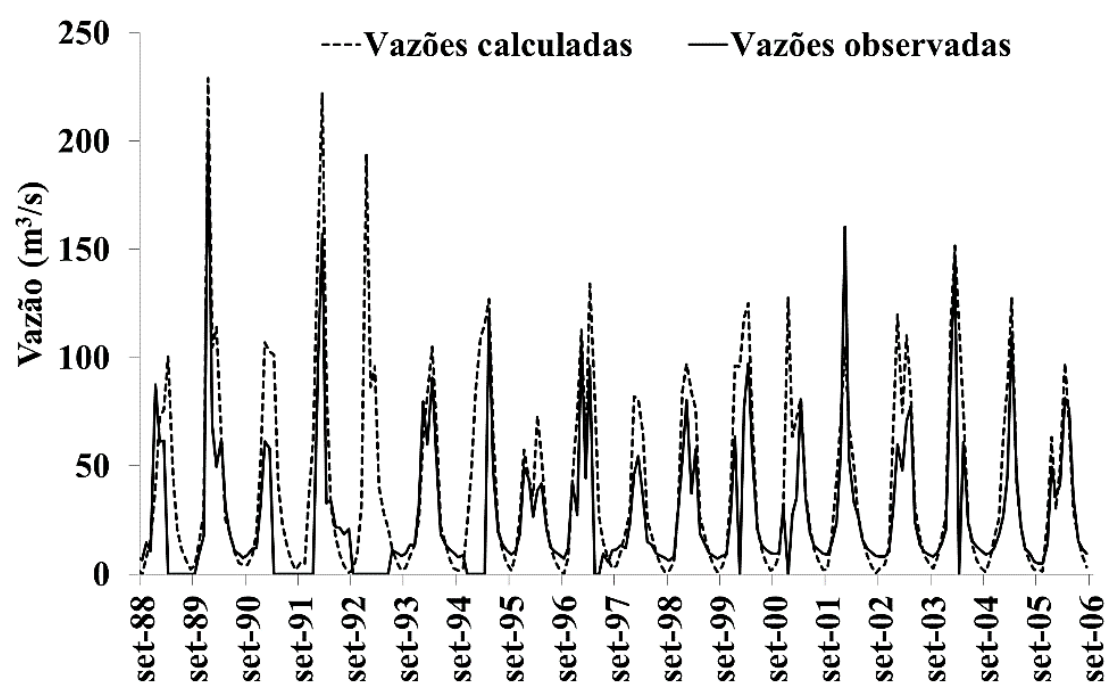

FIGURA 8: Validação em termos das vazões mensais observadas: método AG. FONTE: os autores. 


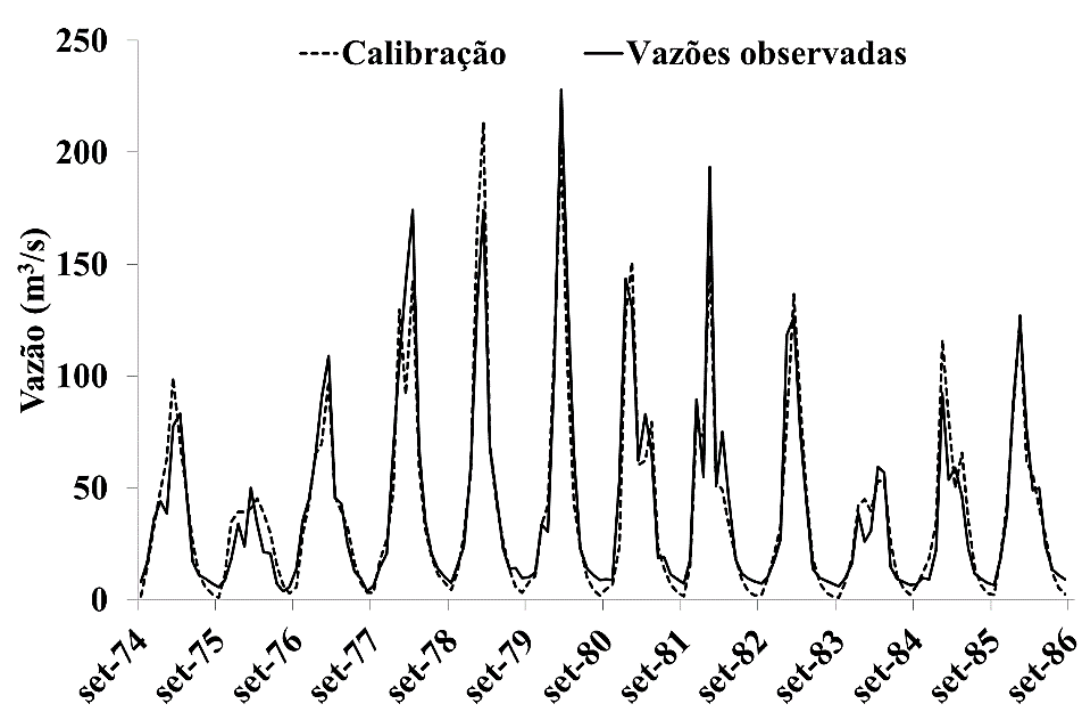

FIGURA 9: Calibração em termos das vazões diárias observadas: método AG. FONTE: os autores.

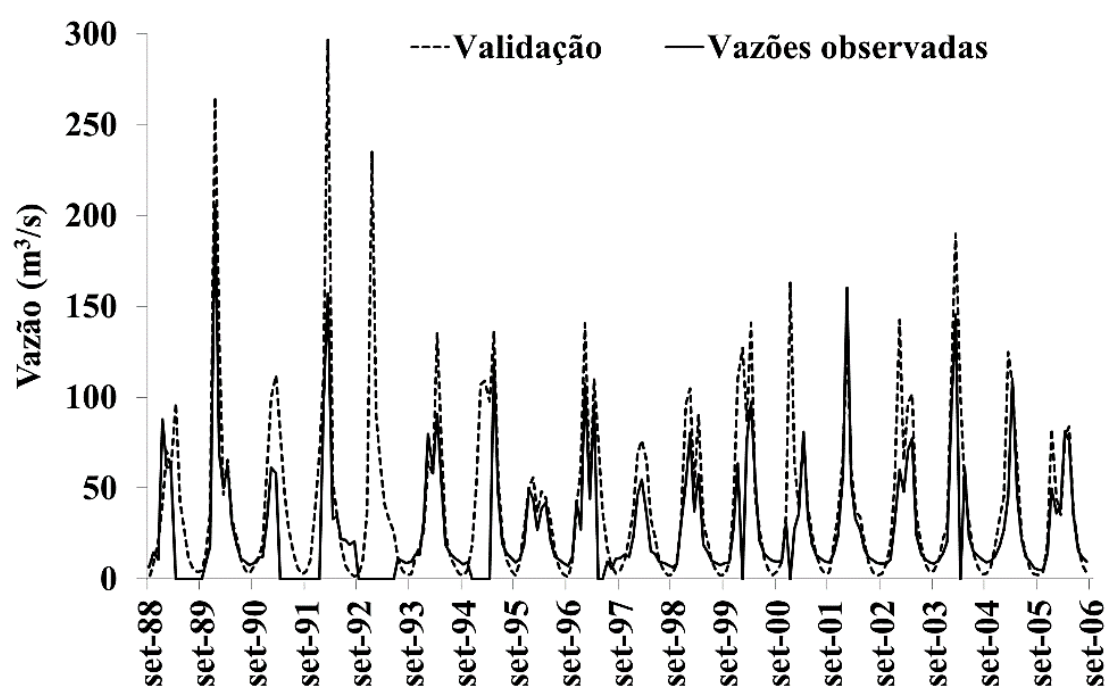

FIGURA 10: Validação em termos das vazões diárias observadas: método AG. FONTE: os autores.

\section{CONCLUSÕES E RECOMENDAÇÕES}

Um modelo chuva-vazão baseado em "tanques" (Tank Model) foi utilizado em conjunto com técnicas de programação não-linear e evolutiva para duas séries históricas de precipitação na Bacia Hidrográfica do Rio Manoel Alves da Natividade, no Estado de Tocantins. O estudo demonstrou ser uma metodologia simples e útil na formulação de uma estrutura de auxílio ao planejamento e gestão dos recursos hídricos de uma bacia hidrográfica. A contribuição do trabalho é que tais estudos são de fundamental importância para regiões carentes de dados climatológicos representativos ou que apresentam falhas longas nos dados das séries de vazões, o que ocorrem com bastante frequência, uma vez que dados observados de vazão são de difícil aquisição e de alto custo, tanto em relação aos equipamentos quanto instalação e monitoramento. Dessa forma, o Tank Model é um modelo de baixíssimo custo que permite a extensão de séries de vazões observadas em séries sintéticas, permitindo simular o comportamento de reservatórios para diversos cenários de uso da água, viabilizando assim, o estudo da hidrologia local.

Neste estudo, o modelo foi representativo em relação à configuração de vazões mensais, pois, com o refinamento da escala temporal, a complexidade da variabilidade da vazão 
diária aumenta progressivamente, gerando problemas na representação da resposta na geração de escoamento, ou seja, tendo como resultado valores que não condizem com a realidade. Dessa forma, não se aconselha a utilização de dados diários para a modelação hidrológica pelo Tank Model para previsão de vazão.

Em relação ao tempo de processamento ser usualmente mais lento que o GRG, não se recomenda a utilização do algoritmo genético para estudos análogos. Ambos encontraram conjunto de soluções semelhantes, evidenciando que, quando aplicados a modelos que possuem configuração simples, ou seja, com função objetivo e restrições simples, o algoritmo a ser empregado não necessita ser complexo. De forma geral, apesar da complexidade que a programação não-linear apresenta, esta é recomendável por possuir formulação matemática geral, sem a necessidade de simplificações, como ocorrem para a programação linear, aumentando assim a precisão dos resultados a serem alcançados.

\section{AGRADECIMENTOS}

À Coordenação de Aperfeiçoamento de Pessoal de Nível Superior (CAPES) e ao Conselho Nacional de Desenvolvimento Científico e Tecnológico (CNPq) pelas bolsas de estudo concedidas aos autores.

\section{REFERÊNCIAS BIBLIOGRÁFICAS}

BRAVO, J. M.; PICCILLI, D. G. A.; COLLISCHONN, W.; TASSI, R.; MELLER, A.; TUCCI, C. E. M. Avaliação visual e numérica da calibração do modelo hidrológico IPH II com fins educacionais. In: XVII Simpósio Brasileiro de Recursos Hídricos, São Paulo, ABRH, p. 1-20, 2007.

FARMER, D.; SIVAPALAN, M.; JOTHITYANKOON, C. Climate, soil, and vegetation controls upon the variability of water balance in temperate and semiarid landscapes: Downward approach to water balance analysis. Water Resour. Res., 39(2), 1035, 2003.

FRANCHINI, M.; PACCIANI, M. Comparative analysis of several conceptual rainfall-runoff models. Journal of Hydrology, Amsterdam, v. 122, n. 1-4, p. 161-219, 1991.
GALVÃO, C. D. O.; VALENÇA, M. J. S. (Orgs.). Sistemas inteligentes: aplicações a recursos hídricos e ciências ambientais. Porto Alegre: Editora UFRGS/ABRH, 1999.

GERMANO, A.; TUCCI, C. E. M.; SILVEIRA, A. L. L. Estimativa dos Parâmetros do Modelo IPH II para Algumas Bacias Urbanas Brasileiras. Revista Brasileira de Recursos Hídricos. RBRH, Porto Alegre, v. 3, n. 4, p. 103-120, 1998.

GOLDBERG, D. Genetic Algorithms in Search, Optimization, and Machine Learning. Addison-Wesley, 1989.

GOVERNO DO ESTADO DO TOCANTINS. Comitê da Bacia Hidrográfica do Rio Manoel Alves. Central - 3. Mar. 2011. Disponível em:<http://central3.to. gov.br/arquivo/111556/>. Acesso em: 19 jul. 2013.

HOLLAND, J. H. Adaptation in natural and artificial systems. Ann Arbor, Issue: 53, Publisher: University of Michigan Press, p.1-200, 1975.

JÚNIOR, A. S.; FARIAS, C. A. S.; SANTOS, C. A. G.; SUZUKI, K. Implementação de um Algoritmo Genético baseado em XML para a calibração do Tank Model. In: XVIII Simpósio Brasileiro de Recursos Hídricos. Associação Brasileira de Recursos Hidricos - ABRH. 2009.

LARA, P. G.; KOBIYAMA, M. Proposta de Modelo Conceitual: PM Tank Model. Revista Brasileira de Recursos Hídricos - RBRH, Volume 17, n 3, p.149-161, 2012.

MAMEDE, F.; GARCIA, P. Q.; WILSON, C. S. J. Relatório Final. Análise de Viabilidade Sócio Econômico Ambiental da Transposição de Águas da Bacia do Rio Tocantins para o Rio São Francisco na Região do Jalapão/TO. Tocantins, 2002.

MONTEITH, J. L. Principles of environmental plysics. Edward Arnold, London, p. 241, 1973.

NASH, J. E.; SUTCLIFFE, J. V. River flow forecasting through conceptual models part I - A discussion of principles. Journal of Hydrology, 10 (3), p. 282-290. 1970.

NICKLOW, J.; REED, P.; SAVIC, D.; DESSALEGNE, T.; HARREALL, L.; CHAN-HILTON, A.; KARAMOUZ, M.; MINSKER, B.; OSTFELD, A.; SINGH, A.; ZECHMAN, E. State of the art for genetic algorithm and beyond in water resources planning and management. Journal Water Resour Plann Manag-ASCE 136(4), p. 412-432, 2010.

RECHENBERG, I. Evolutiosstrategie: Optimierung technischer Systeme nach Prinzipien der biologischen Evolution. Frommann-Holzboog, Stuttgart, 1973.

SANTOS, C. A. G.; FREIRE, P. K. M. M.; MISHRA, S. K.; JÚNIOR, A. S. Application of a particle swarm optimization to the tank model. IAHS- International Association of hydrological sciences, AISH Publication, v.347, p.114-120, 2011. 
SINGH, A. Irrigation Planning and Management through

Optimization Modelling. Water Resources

Management, vol. 28 p.1-14. 2014.

THORNTHWAITE, C.W.; MATHER. J .R. Instructions and tables for computing potencial evapotranspiration and the water balance. Centerton, Drexel Institute of Technology, Publications in Climatology, v. 10, n. 3. p. 311, 1957.

TUCCI, C.E.M.; ORDONEZ, J.S.; SIMÕES LOPES, M. Modelo Matemático Precipitação-Vazão IPH II Alguns Resultados. Anais IV Simpósio Brasileiro de Recursos Hídricos. ABRH. Fortaleza. 1981.

WORLD METEOROLOGICAL ORGANIZATION. Intercomparison of conceptual models used in operational hydrological forecasting. Geneva: World Meteorological Organization, Operational hydrology report, n. 7, WMO publication, n. 429, p. 172, 1975. 